\title{
RESEARCH
}

Open Access

\section{Safety of house dust mite subcutaneous immunotherapy in preschool children with respiratory allergic diseases}

Yaqi Yang, Dongxia Ma, Nan Huang, Wenjing Li, Qing Jiang, Yin Wang, Xiaolong Wang, Lin Yang and Rongfei Zhu* (10)

\begin{abstract}
Background: Allergen immunotherapy (AIT) is the only causal therapy for IgE-mediated allergy. There is less evidence about the safety and efficacy of AlT especially subcutaneous immunotherapy (SCIT) in children under 5 years old. We aimed to investigate the side effects and associated risk factors of house dust mite (HDM) SCIT in preschool children with respiratory allergic diseases.

Methods: The preschool children who had HDM-related allergic rhinitis with/without asthma were enrolled and undergone standardized HDM SCIT in our department from June 2013 to December 2019. Local reactions (LRs) and systemic reactions (SRs) were recorded and categorized according to World Allergy Organization recommendations. Demographic data and other therapeutic-related parameters were also recorded to investigate potential risk factors for these side effects.

Results: A total of 91 children (60 boys, 65.93\%; 31 girls, 34.07\%; mean age 4.13 years old) were included in the study. Among the 91 patients, 3109 SCIT injections were recorded, 62/91 (68.13\%) experienced 186 immediate LRs, 4 /91(4.40\%) experienced 6 delayed LRs, 11/91 (12.09\%) children experienced 44 immediate SRs, 21/44 (47.73\%) were grade 1 SRs, $21 / 44$ (47.73\%) were grade 2, 2/44 (4.55\%) were grade 3, no grade 4 or 5 SRs occurred.

Furthermore, $1 / 91$ (1.10\%) experienced 1 delayed SRs, manifested by urticaria 2 days later after allergen injection. 9/ 91 (9.89\%) experienced 2 or more times SRs. Multivariable logistic regression analysis showed BMI (OR 1.506; 95\%Cl 1.091 to $2.079 ; p<0.05)$ and slgE against HDM (OR 1.497; 95\%Cl 1.082 to $2.071 ; p<0.05)$ were risk factors for LRs. No variable was found to correlate with SRs (all $p>0.05$ ).

Conclusions: HDM subcutaneous immunotherapy is considered to be safe in preschool children with respiratory allergic diseases. Higher BMI and HDM slgE level in children are risk factors for developing LRs. The incidence of SRs and the rate of severe SRs are low in preschool children.
\end{abstract}

Keywords: Subcutaneous immunotherapy, House dust mite, Allergic rhinitis, Asthma, Side effect

\section{Background}

Allergen immunotherapy (AIT) can induce immune tolerance to allergens and has a disease-modifying effect for immunoglobulin E (IgE)-mediated allergic diseases

\footnotetext{
* Correspondence: zrf13092@163.com

Department of Allergy, Tongji Hospital, Tongji Medical College, Huazhong University of Science and Technology (HUST), Wuhan 430030, Hubei, China
}

$[1,2]$. When allergen extracts are administered, immune responses are elicited, including the activation of specific blocking antibodies (eg. IgG4), tolerance-inducing cells (eg. regulatory $\mathrm{T}$ and $\mathrm{B}$ cells), and mediators (eg.cytokines including IL-10 and TGF- $\beta$ ) [1]. These responses prevent further exacerbation of the allergen-triggered immune response and attenuate the inflammatory

(c) The Author(s). 2021 Open Access This article is licensed under a Creative Commons Attribution 4.0 International License, which permits use, sharing, adaptation, distribution and reproduction in any medium or format, as long as you give appropriate credit to the original author(s) and the source, provide a link to the Creative Commons licence, and indicate if changes were made. The images or other third party material in this article are included in the article's Creative Commons licence, unless indicated otherwise in a credit line to the material. If material is not included in the article's Creative Commons licence and your intended use is not permitted by statutory regulation or exceeds the permitted use, you will need to obtain permission directly from the copyright holder. To view a copy of this licence, visit http://creativecommons.org/licenses/by/4.0/. The Creative Commons Public Domain Dedication waiver (http://creativecommons.org/publicdomain/zero/1.0/) applies to the data made available in this article, unless otherwise stated in a credit line to the data. 
response in tissues [1,3]. AIT also appears to have a long-term clinical efficacy of up to 12 years even after treatment cessation [4]. In addition, AIT prevents the development of asthma and hypersensitivity to novel allergens [5]. As AIT is the only causal treatment for IgEmediated allergy, the World Allergy Organization (WAO) recommend AIT can be considered as initial treatment and failure of pharmacotherapy is not an essential prerequisite of the use of AIT [6]. For respiratory allergy, AIT may be proposed as an early treatment in the therapeutic strategy $[1,6]$. However, in several AIT guidelines $[1,6]$, the lower age limit for children eligible for this treatment is set at 5 probably for concerns that children under 5 show less cooperation and limited ability to report the early signs and symptoms of severe allergic side-effects in the age. These concerns are understandable but not necessarily well-supported by evidence.

It is well known that natural history or typical progression of allergic diseases (namely allergy march) such as atopic dermatitis, food allergy, allergic rhinitis (AR) and asthma often begin early in life, while AIT is the only treatment that may alter the progression of allergic diseases $[7,8]$, the decision of initial AIT in age below 5 years old group always depends on how to balance the benefit of early intervention and risk of potential side effects. For safety concerns, children under 5 have been listed in the EAACI guideline as a relative contraindication of AIT, both in sublingual immunotherapy (SLIT) and subcutaneous immunotherapy (SCIT). However, some studies had shown that SLIT in children below 5 years old were effective and there was no difference in the safety profile in this age group and older children. One study included children aged 2-5 years receiving SLIT for house dust mite (HDM) allergy, only mild-tomoderate local adverse reactions were reported [9]. For SCIT, there have been reported a relative higher risk of side effects including local reactions (LRs) and systemic reactions (SRs) than SLIT. In SCIT trials, SRs occurred in $6-17 \%$ of pediatric asthma patients [10], grade 1 reactions were the most frequent in both adults and children [11]. There are limited studies of SCIT in under-five age group. A retrospective study of SCIT in 239 children below the age of 5 years (8-59 months old), who received a total of 6689 injections, reported a single systemic reaction $90 \mathrm{~min}$ after an injection in a 3-year-old boy [12]. According to current data, adverse effects of AIT were not more frequent or more severe in children below 5 years old group.

HDM is one of the most common sources of indoor allergens and can trigger perennial AR, asthma. Our previous study found that HDMs were the major aeroallergens among AR patients in central China, with a sensitization rate of over $90 \%$. In the confirmed AR children below 6 years old, the sensitization rate of HDM [including Dermatophagoides farina (Df) and Dermatophagoides pteronyssinus (Dp)] was 97.6\% [13]. SCIT with commercial HDM extracts of Dp (Alutard SQ, ALK Hørsholm, Denmark) have been demonstrated to be effective in children with AR and/or asthma [14-16]. This study aimed to investigate the incidence of side effects and potential risk factors during HDM SCIT in preschool children with respiratory allergy.

\section{Methods}

\section{Design and participants}

We conducted a prospective study among preschool children treated by SCIT in the Department of Allergy, Tongji Hospital. Participants included preschool children treated by standardized SCIT with Alutard Dp vaccine, from June 2013 to December 2019. The study was approved by the Independent Ethical Committee of Tongji Hospital, and each participator's statutory guardian signed the informed consent of the immunotherapy and this study. The inclusion criteria were as follows: (1) aged $\leq 5$ years; (2) diagnosed with AR with or without asthma according to the Allergic Rhinitis and its Impact on Asthma Guidelines(ARIA) [17] and Global Initiative for Asthma (GINA) (https://ginasthma.org/); (3) positive skin-prick tests (a wheal diameter $\geq 3 \mathrm{~mm}$ ) to Df and Dp (Macro-Union Pharmaceutical, Beijing, China) and serum specific IgE (sIgE) against Df and $\mathrm{Dp} \geq 0.7 \mathrm{kU} / \mathrm{L}$ (Thermo-Fisher, Uppsala, Sweden); (4) allergic symptoms of AR and/or asthma after exposure to HDM; (5) received at least one dosage HDM vaccine injection. The exclusion criteria were as follows: (1) sensitization and symptoms after exposure to other allergens ( $\operatorname{IgE} \geq 0.7$ $\mathrm{kU} / \mathrm{L}$ ) such as pollens and molds, and experiencing symptoms after allergen exposure; (2) presence of autoimmune diseases, primary immunodeficiency diseases, type III allergic diseases and neoplasia.

\section{Treatment}

The treatment regimen was set up according to the conventional schedule provided by the manufacturer (Alutard SQ, ALK Hørsholm, Denmark). During the buildup phase of SCIT, patients received weekly injections at a dose of $0.2,0.4$, and $0.8 \mathrm{~mL}$ in No. $1(100 \mathrm{SQ} / \mathrm{mL})$, No.2 $(1000 \mathrm{SQ} / \mathrm{mL})$ to No.3 vials $(10,000 \mathrm{SQ} / \mathrm{mL})$ and $0.1,0.2,0.4,0.6,0.8$, and $1.0 \mathrm{~mL}$ in No. 4 vial $(100$, 000SQ/mL, contains $9.8 \mu \mathrm{g}$ Der $p 1$ per mL) [13] until reaching an optimal dose. Subsequently, the maintenance dose was given every $4-6$ weeks for 3-5 years. Before each injection, patients were required to undergo the following: (1) physical examination; (2) peak expiratory flow (PEF) test (measured by a portable mini peak flowmeter, Wanbo Technology Co., Ltd., Shanghai), patients with $\mathrm{PEF}<80 \%$ of the predicted value (or personal 
best value) were not allowed to receive allergen injection); (3) pulmonary function testing, recorded forced expiratory volume in $1 \mathrm{~s}$ (FEV1) (measured by an Easy$\mathrm{One}^{\mathrm{Tw}}$ spirometry, NDD Co.,LTD, Switzerland), patients with FEV $1<80 \%$ of the predicted value (or personal best value) were not allowed to receive injection. Both PEF and FEV1 were detected only in children above the age of 4 ; (4) assessment of side effects (especially delayed local and systemic reactions provided by their parents) since last injection. Patients were kept in the clinic for at least $30 \mathrm{~min}$ after each injection. Patients who experienced SRs were treated with rescue medications immediately and monitored carefully. If delayed LRs and/or SRs happened, the parents were asked to report to our center, and the doctors would determine further treatment.

\section{Combined symptom medication score (CSMS)}

We evaluated the efficacy of SCIT by combined symptom medication score (CSMS), which was based on an equal weight of the daily symptom score (dSS) (0-3) and of the daily medication score (dMS) $(0-3)$ in the daily total CSMS (0-6) according to AIT position paper [18]. We recorded the visual analog scale (VAS; a straight line was scaled as 0 to $10 \mathrm{~cm}$, with " 0 " indicating "no symptoms" and "10" for "most serious symptoms" [18]): parents assessed the nasal symptoms of children in the past 3 days before injection. We converted the mean VAS score (ranged from "0" to "10") within 180 days into symptom score (ranged from "0" to " 3 "). For example, if one patient's VAS scores were " 5 ", " 5 ", "4" and "4" during the past 180 days, then the mean VAS score was $(5+5+4+4) / 4=4.5$, the symptom score would be $4.5 * 3 / 10=1.35$. As it was impractical to record the daily medication score (dMS) in in this open-labelled noncontrolled 3-year prospective study, we calculated the total medication amounts within 180 days and converted that into the average medication dose. The medication scoring criteria were as following:" 0 " for "no medication"; "1" for "180-day dose of oral nonsedative H1 antihistamines (H1A) (the standard dose was $5 \mathrm{mg}$ loratadine daily or equal)"; " 2 " for " 6 bottles of mometasone furoate nasal spray (180 sprays) or equal dose of other nasal steroid spray", the total medication score was ranged from "0" to " 3 ". For example, if one patient used 1 bottle of mometasone furoate nasal spray and $120 \mathrm{mg}$ loratadine within 180 days, then the medication score would be $[(1 / 6) * 2+120 /(180 * 5)]=0.46$. The CSMS was the sum of symptom score and medication score, ranging from "0" to " 6 ".

\section{Side effects}

Side effects were documented at the time of each injection, including LR and SR. Erythema and/or swelling at the injection area were defined as large $\mathrm{LR}(\geq 4 \mathrm{~cm}$ in diameter) $[19,20]$. SRs were classified into 5 grades, ranging from grade 1 (symptoms of one organ system present) to grade 5 (death) according to the AIT Systemic Reaction Grading System proposed by WAO [21, 22]. In our study, the side effects were further classified into immediate (appearance within $60 \mathrm{~min}$ after injection) and delayed (occurring after $60 \mathrm{~min}$ ) side effects.

\section{Statistical analysis}

STATA 15.1 (StataCorp, College Station, Texas 77,845 USA) was used for data analysis. All variables were converted into numeral values and analyzed as absolute or relative frequencies, mean and standard deviation (SD) to describe the demographic data, diagnostic, therapeutic parameters and side effects.

2-sample $t$ test was used to evaluate the continuous variable. The Pearson chi-square test and Fisher's exact test were used to determine the association between categorical variables. Odds ratios (ORs) between groups were calculated and $95 \%$ confidence intervals (CIs) were generated. For the multivariable analysis, logistic regression, with forwarding model selection and the likelihood ratio test, was applied to assess the predictive model of the dependent variable. All tests were performed 2tailed, and $p<0.05$ was considered statistically significant.

\section{Results \\ Study population}

In total, 91 preschool patients (60 boys, 65.93\%; 31 girls, $34.07 \%$ ) were included in this study. The mean age was $4.13 \pm 0.57$ years old. Of the patients, $80(87.91 \%)$ had AR, 11(12.09\%) had AR with asthma. The mean number of injections per patient was $34.17 \pm 16.00$, the mean length of SCIT was $105.50 \pm 70.39$ weeks (Table 1 ).

\section{Incidence of side effects}

In total, 91 preschool patients received 3109 injections, 62 (68.13\%) experienced 186 (5.98\%) immediate LRs, 11 (12.09\%) experienced 44 (1.42\%) immediate SRs, 9 (9.89\%) experienced $\geq 2$ times SRs, $4(4.40 \%)$ experienced 6 (0.19\%) delayed LRs, 2 (2.20\%) experienced $\geq 2$ times delayed LRs and relieved in three days without extra medication. 1/91 (1.10\%) experienced delayed $1 \mathrm{SR}$ in the build-up period, manifested by mild urticaria 2 days later after allergen injection, the symptoms were relieved in one day after taken oral anti-histamine medication.

\section{Severity of side effects}

Among the 44 immediate SRs, 97.73\% (43/44) occurred during No. 4 vial $(100,000 \mathrm{SQ}-\mathrm{U} / \mathrm{mL})$ injection, $47.73 \%$ (21/44) were grade 1 SRs, $47.73 \%$ (21/44) were grade 2, $4.55 \%(2 / 44)$ were grade 3 , no grade 4 or 5 SRs occurred. 
Table 1 Demographic data

\begin{tabular}{ll}
\hline Characteristics & $\mathbf{n = 9 1}$ \\
\hline Gender & $60(65.93)$ \\
Male, $\mathrm{n}(\%)$ & $31(34.07)$ \\
Female, $\mathrm{n}(\%)$ & $4.13(0.57)$ \\
Age (years), mean (SD) & $15.48(1.64)$ \\
BMI (kg/m^2), mean (SD) & \\
Diagnosis & $80(87.91)$ \\
AR, $\mathrm{n}(\%)$ & $11(12.09)$ \\
AR with asthma, $\mathrm{n}(\%)$ & \\
Family history & $54(59.34)$ \\
None, $\mathrm{n}(\%)$ & $23(25.27)$ \\
Father, $\mathrm{n}(\%)$ & $14(15.38)$ \\
Mother, $\mathrm{n}(\%)$ & \\
AD in infancy & $53(58.24)$ \\
Yes, $\mathrm{n}(\%)$ & $38(41.76)$ \\
No, $\mathrm{n}(\%)$ & \\
Food allergy history & 35 (38.46) \\
Yes, $\mathrm{n}(\%)$ & $58(63.74)$ \\
No, $\mathrm{n}(\%)$ & $50.23(38.35)$ \\
Dp slgE at baseline (KU/L), mean (SD) & $34.17(16.00)$ \\
Injections per patient, mean (SD) & $105.50(70.39)$ \\
Length of SCIT (weeks), mean (SD) & \\
\hline BMI body mass index, AR allergic rhinitis, AD Atopic dermatitis, SD standard \\
deviation, Dp Dermatophagoides pteronyssinus, slgE specific immunoglobulin \\
E, SCIT subcutaneous immunotherapy
\end{tabular}

The mean reaction dose of SRs was 55,245.45 \pm 24 , 594.38 SQ (approximate $0.55 \mathrm{ml}$ of Vial No.4). The symptoms/signs of the SRs included conjunctival pruritus, rhinitis symptoms, itchy throat, cough not related to bronchospasm, urticaria and generalized pruritus, asthma symptoms/signs (cough, wheezing, shortness of breath), declines in PEF or FEV1 and abdominal cramps (Table 2). The patients with SRs responded rapidly to rescue medications such as oral $\mathrm{H} 1$ antihistamines and inhaled $\beta 2$ agonists. Both patients with grade 3 had treatment with intramuscular epinephrine.

Among the 64 patients with side effects, 82.81\% (53/ 64) experienced first side effect during No.4 vial injection, $87.5 \%(56 / 64)$ had LRs as the first side effects (Fig. 1). In total, $26.37 \%(24 / 91)$ patients couldn't reach the maximum dosage recommended by the manufacturer (100,000SQ), $75 \%(18 / 24)$ of them were because of large LR, $25.00 \%(6 / 24)$ of them were because of SRs. No patient dropped out due to pain or large LRs.

\section{Risk factors of LRs and SRs}

Nine variables including demographic factors and Dp sIgE level were included in the analysis, only the BMI were found to correlated to LRs (OR 1.419; 95\%CI,1.053 to $1.913 ; p<0.05$ ) (Table 3 ). However, multivariable logistic regression analysis showed BMI (OR 1.506; 95\%CI, 1.091 to 2.079; $p<0.05$ ) and Dp sIgE level (OR 1.497; $95 \% \mathrm{CI}, 1.082$ to $2.071 ; p<0.05)$ were risk factors for LRs.

Ten variables were included in SR analysis, only the LRs showed a correlation to SRs (OR 1.231; 95\%CI,1.018 to $1.488 ; p<0.05$ ) (Table 4 ). However, in the multivariable logistic regression analysis, no variables were found to have correlation to SRs (all $p<0.05)$.

\section{Correlation between side effects and SCIT efficacy}

The CSMS showed a decline trend in this population, from $4.47 \pm 0.95$ at baseline to $1.94 \pm 0.47$ at year 1 , $1.45 \pm 0.37$ at year 2 and $1.31 \pm 0.43$ at year 3 (all $p<0.05$ compared with baseline). However, no correlations were found among the side effects and SCIT efficacy in this population. The CSMS were similar in the patients with LRs and without LRs, as well as the patients with/without SRs $(p>0.05)$ (Fig. 2).

\section{Discussion}

Allergen immunotherapy in preschool children is always a dilemma for the physicians. On the one hand, there

Table 2 Manifestations and severity of systemic reactions

SRs

SR rates (\%o of injections) $N=3109$

Organ systems involved

Conjunctival (pruritus)

Upper respiratory (rhinitis, itchy throat or cough not related to bronchospasm)

Cutaneous (urticaria and generalized pruritus)

Lower respiratory (asthma, wheezing rhonchi or drop of PEF or FEV1)

Gastrointestinal (abdominal cramps)

Grade 1

Grade 2

1

20

2

21

1

21

21

Grade 3
0.32

6.43

0.64

6.75

0.32

6.75

6.75

0.64

$S R$ systemic reaction, PEF peak expiratory flow, FEV1 forced expiratory volume in $1 \mathrm{~s}$ 


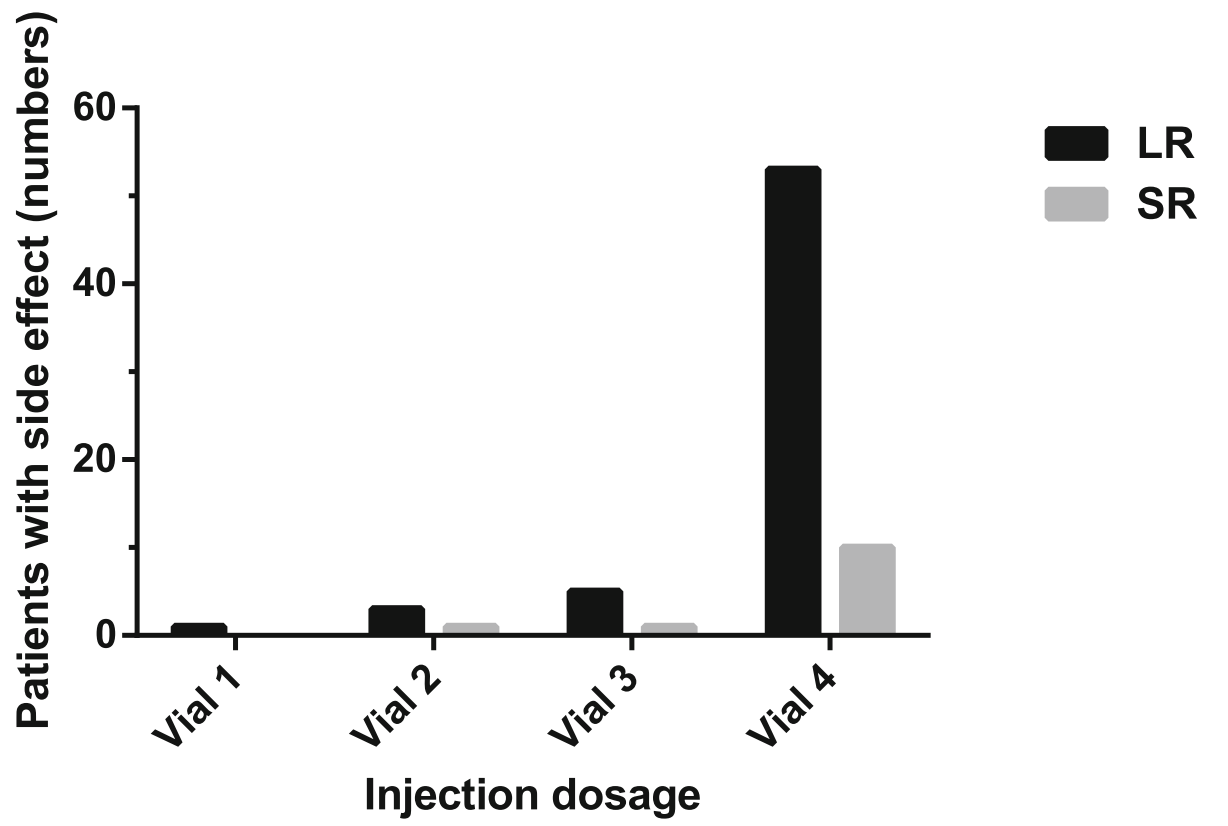

Fig. 1 Patients experienced side effects in different dosages

are strong evidences to support early introduction of AIT to prevent allergy march $[7,8]$; on the other hand, younger children always show stronger resistance to AIT and cannot depict their symptoms accurately when adverse reactions happen. Moreover, they have often upper respiratory infections resembling allergic symptoms. Recently some studies suggested SLIT was rarely associated with moderate or severe SRs and SLIT was considered to be safe in children younger than 5 years old [23, 24]. However, due to the limited studies of SCIT and SLIT in under-five age group, most guidelines have no recommendation of AIT in this population. In our study, we investigated the safety profile of the HDM SCIT in preschool children by examining the incidence of LRs and

Table 3 Univariable Predictors of LRs

\begin{tabular}{lll}
\hline Variable & $\boldsymbol{p}$ & OR(95\%Cl) \\
\hline Age & 0.688 & \\
Gender & 0.595 & 1.419 (1.053-1.913) \\
BMl & $0.022^{*}$ & \\
Diagnosis & 0.558 & \\
Disease duration & 0.596 & \\
AD in fancy & 0.159 & \\
Food allergy history & 0.943 & \\
Family history & 0.328 & \\
Dp slgE & 0.074
\end{tabular}

$O R$ odds ratio, $C l$ confidence interval, $B M I$ body mass index, $A D$ Atopic dermatitis, $D p$ Dermatophagoides pteronyssinus, slgE specific immunoglobulin Es ${ }^{*} p<0.05$
SRs with conventional SCIT regimen. We found that the HDM SCIT could be considered safe in preschool children with respiratory allergic diseases. In addition, during maintenance phase one subcutaneous injection per month was adequate in order to maintain efficacy of SCIT.

The immediate LRs in preschool patients were common in our study. Nearly $70 \%$ of our patients experienced immediate LRs during SCIT. It is easy to understand that the majority of LRs happened in high dosage HDM extracts (No.4 vial) injection. The incidence of immediate LRs in preschool patients was similar to that observed in patients aged 5-60 years in our

Table 4 Univariable Predictors of SRs

\begin{tabular}{|c|c|c|}
\hline Variable & $p$ & $\mathrm{OR}(95 \% \mathrm{Cl})$ \\
\hline Age & 0.780 & \\
\hline Gender & 0.864 & \\
\hline BMI & 0.625 & \\
\hline Diagnosis & 0.099 & \\
\hline Disease duration & 0.705 & \\
\hline$A D$ in fancy & 0.699 & \\
\hline Food allergy history & 0.879 & \\
\hline Family history & 0.228 & \\
\hline Dp slgE & 0.079 & \\
\hline LR & $0.032^{*}$ & $1.231(1.018-1.488)$ \\
\hline
\end{tabular}



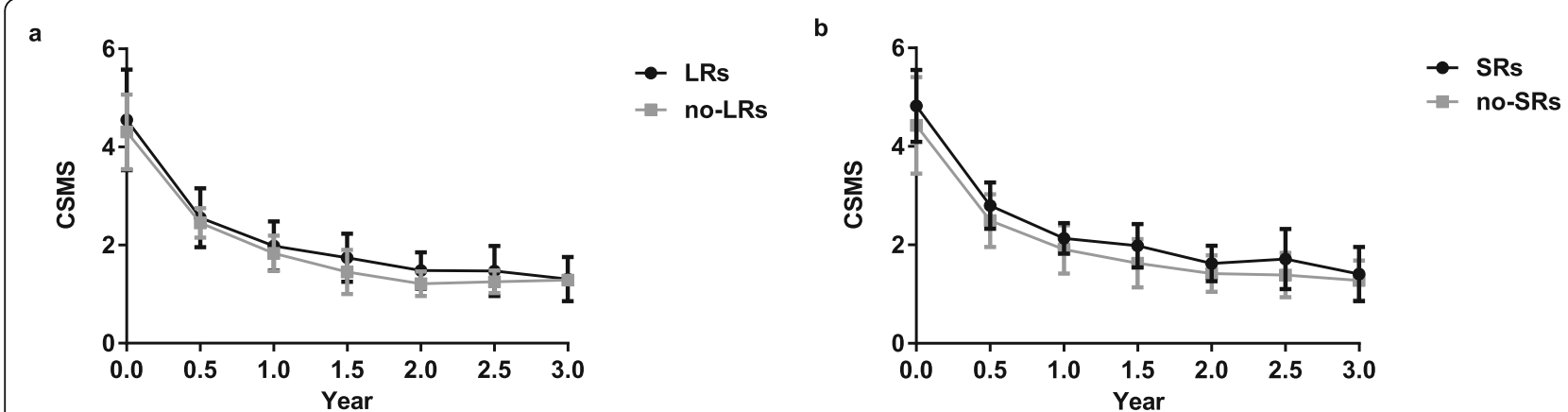

Fig. 2 The CSMS in different years. a The CSMS were no differences in the patients with LRs and without LRs ( $p>0.05$ ); $\mathbf{b}$ The CSMS were no differences in the patients with SRs and without SRs $(p>0.05)$

previous study [15]. This suggests that SCIT in age below 5 years old group is as tolerable as for children aged above 5 and adults. Some reports showed that up to $93 \%$ of patients experienced immediate LRs during SCIT $[10,25,26]$. The differences of immediate LRs rates may be due to the allergen type and allergen extracts used in different studies. For example, pollen extracts and depot allergen extracts were easier to evoke LRs than HDM and aqueous allergen extracts [27]. The $\mathrm{HDM}$ vaccine we used in our study were $\mathrm{Al}(\mathrm{OH}) 3$ absorbed sustain-released extracts, which may lead to a relatively high incidence of LRs. Interestingly, the delayed LRs appeared less than those in other studies, it might be related to the knowledge and judgment of the parents, as the delayed LRs were usually recorded in home, sometimes the delayed LRs records were missing. Risk factors analysis showed that children with high specific IgE level and high BMI were prone to develop LRs. We speculate this might be due to that the adipose tissue limited the diffusion of allergen extracts in high BMI children. However, this finding needs to be validated in larger population. Since LRs usually disappeared in a period ranging from several hours to 3 days and didn't need any medical intervention in most cases, the attempt to reduce LRs by dosage adjustment may not be necessary in this population, unless large LRs happens and the LRs become intolerable.

We found the incidence of immediate and delayed SRs in the preschool patients was similar to that previously reported in children [28-30], $12.09 \%$ of the population experienced SRs during SCIT. In some Chinese patients' studies, SRs occurred in $12.26-18.49 \%$ of patients and $0.72-3.28 \%$ of injections in children. We also found the majority of the SRs were grade 1 and grade 2 reactions, which was consistent with previous studies [31, 32]. Only 2 /91 (4.55\%) patients experienced grade 3 reactions within $30 \mathrm{~min}$ after injection and responded well to rescue medication, no patient had grade 4 or grade 5 reaction. These indicated that SCIT in age below 5 years old was as safe as in older children. Indeed, to assure the safety of these patients, we took an extra procedure that all the patients-including AR patients- to finish the PEF test before each injection. One challenge was that the younger children might not get the PEF value accurately. Thus, we didn't expect the accuracy but require the good repeatability of the data. These mutuallyconfirmed data obtained from mini-PEF flowmetry and portable spirometry were utilized to ensure the eligibility to receive allergen injection. The preschool patients would postpone their injection if the PEF value didn't achieve $80 \%$ of their predict value (or personal best value), which might be helpful to reduce the incidence of SRs in this population. Despite the extra step we had taken in our study, we still found the incidence of SRs were slightly higher than those in adolescents or adults (0.31-1.47\% of injections, $5.68-10.98 \%$ of patients) [14, 30]. Another study also showed that the incidence of side effects was higher in the preschool ( 2 to 6 years old) group than the older ( 7 to 18 years old) group [33]. Considering that the majority of SRs happened in high dose allergen injection (usually Vial No.4) and the preschool children shared the same treatment regimen with the adolescents and adults, the maximum tolerable dosage in this population needs to be further investigated to make the balance between efficacy and safety. The dose of HDM extracts would be appropriately reduced after SRs if SCIT was continued, we usually reduced the dose to one that was previously tolerated or an even lower dose if the reaction was severe [34].

We found that LRs showed a correlation to SRs, but this correlation was not confirmed in the multivariable logistic regression analysis. Indeed, the correlation between LRs and SRs is still in controversy. Previous studies indicate that individual local reactions do not appear to be predictive of subsequent SRs. However, some patients with a greater frequency of large LRs might be at an increased risk of future SRs [34]. In our study, the children with large LRs would reduce their allergen dosage in the next injection as Cox et al. suggested [34], which might help to decrease the risk of SRs. Asthma 
(especially moderate asthma) has been identified as a risk factor for SRs in many studies [14, 35, 36]. However, asthma was not a risk factor for SRs in our population, which might be attributed to the fact that all of the 11 asthmatic children have mild asthma, and also the standardized pre-treatment evaluation procedure and careful allergen-dose adjustment during SCIT, as more than $1 / 4$ of our preschool patients didn't reach the recommended maintenance dosage (100,000 SQ) for adolescents and adults. We also found other variables including age and disease duration had no correlation with SRs. In other words, the SRs sounds to be unpredictable in the preschool patients, we need to be very caution for each injection to recognize the early signs of SRs in time.

Some limitations hampered our study. Firstly, we did not have placebo group (only contain adjuvant) and older-age group serveing as control group. Thus, this study was meant to be regarded as a descriptive research and the safety profile in this study needs to be interpreted with caution. Secondly, it is quite challenge to acquire the accurate value of PEF and FEV1 in these younger-age population. For this reason, we couldn't present the lung function data in the results as evidence of SCIT efficacy. Instead, we listed this step as a part of pre-injection procedure in the SCIT. Finally, the number of children with asthma (11/91) was small in our study, which might lead to bias and made it difficult to evaluate the correlation between asthma and SCIT-related adverse reactions. More asthma cases are needed in further studies to figure out the relationship between asthma and SCIT safety in the preschool children.

\section{Conclusions}

Our study demonstrates that HDM SCIT is considered to be safe in preschool children with respiratory allergic diseases. The incidence of SRs is low and the severity of SRs ranges from mild to moderate in the preschool patients. LRs and SRs usually happen when high dosage allergen vaccine is administrated. Children with higher BMI and HDM sIgE level are prone to develop LRs. A comprehensive pre-treatment evaluation and careful allergen-dosage adjustment help to decrease the side effects of HDM SCIT in the preschool children.

\footnotetext{
Abbreviations

AIT: Allergen immunotherapy; IgE: Immunoglobulin Es; WAO: World Allergy Organization; AR: Allergic rhinitis; SLIT: Sublingual immunotherapy; SCIT: Subcutaneous immunotherapy; HDM: House dust mite; LR: Local reaction; SR: Systemic reaction; Df: Dermatophagoides farinae; Dp: Dermatophagoides pteronyssinus; ARIA: Allergic Rhinitis and its Impact on Asthma Guidelines; GINA: Global Initiative for Asthma; PEF: Peak expiratory flow; FEV1: Forced expiratory volume in $1 \mathrm{~s}$; CSMS: Combined symptom medication score; VAS: Visual analog scale; DSS: Daily symptom score; DMS: Daily medication score; SD: Standard deviation; OR: Odds ratio; $\mathrm{Cl}$ : Confidence interval
}

\section{Acknowledgements}

We thank all participants and investigators in this study. We also thank Dr. Xiubo Zhu for her invaluable assistance throughout the preparation of the manuscript.

\section{Authors' contributions}

YQY contributed to the design of the study, analysis of data and the drafting of the article. DXM, NH and WJL participated in enrolled the patients. QJ, YW $X L W$ and $L Y$ participated in the collection of clinical samples and experimental data. RFZ designed the study and made critical revisions of the article for important intellectual content. All authors read and approved the final manuscript.

\section{Funding}

Young and Middle-aged Backbone Personnel Training Program of Wuhan (NO.2018QNYX003).

\section{Availability of data and materials}

All data generated or analyzed during this study are included in this published article.

\section{Declarations}

Ethics approval and consent to participate

The study was approved by the Independent Ethical Committee of Tongji Hospital, and each participator's statutory guardian signed the informed consent of the immunotherapy and this study.

Consent for publication

Not applicable.

\section{Competing interests}

The authors declare that they have no competing interests.

Received: 13 January 2021 Accepted: 9 April 2021

Published online: 23 April 2021

\section{References}

1. Alvaro-Lozano M, Akdis CA, Akdis M, Alviani C, Angier E, Arasi S, et al. EAACl allergen immunotherapy User's guide. Pediatr Allergy Immunol. 2020; 31(Suppl 25):1-101. https://doi.org/10.1111/pai.13189.

2. Sokolowska M, Boonpiyathad T, Escribese MM, Barber D. Allergen-specific immunotherapy: power of adjuvants and novel predictive biomarkers. Allergy. 2019;74(11):2061-3. https://doi.org/10.1111/all.13973.

3. Pfaar O, Bachert C, Bufe A, Buhl R, Ebner C, Eng P, et al. Guideline on allergen-specific immunotherapy in IgE-mediated allergic diseases: S2k Guideline of the German Society for Allergology and Clinical Immunology (DGAKI), the Society for Pediatric Allergy and Environmental Medicine (GPA), the Medical Association of German Allergologists (AeDA), the Austrian Society for Allergy and Immunology (OGAI), the Swiss Society for Allergy and Immunology (SGAI), the German Society of Dermatology (DDG), the German Society of Oto- Rhino-Laryngology, Head and Neck Surgery (DGHNO-KHC), the German Society of Pediatrics and Adolescent Medicine (DGK)), the Society for Pediatric Pneumology (GPP), the German Respiratory Society (DGP), the German Association of ENT Surgeons (BV-HNO), the Professional Federation of Paediatricians and Youth Doctors (BVKJ), the Federal Association of Pulmonologists (BDP) and the German Dermatologists Association (BVDD). Allergo J Int. 2014;23:282-319.

4. Eng PA, Borer-Reinhold M, Heijnen IA, Gnehm HP. Twelve-year follow-up after discontinuation of preseasonal grass pollen immunotherapy in childhood. Allergy. 2006;61(2):198-201. https://doi.org/10.1111/j.1398-9995.2 006.01011.x.

5. Jacobsen L, Niggemann B, Dreborg S, Ferdousi HA, Halken S, Host A, et al. Specific immunotherapy has long-term preventive effect of seasonal and perennial asthma: 10-year follow-up on the PAT study. Allergy. 2007;62(8): 943-8. https://doi.org/10.1111/j.1398-9995.2007.01451.x

6. Canonica GW, Bachert C, Hellings P, Ryan D, Valovirta E, Wickman M, et al. Allergen immunotherapy (AIT): a prototype of precision medicine. World Allergy Organ J. 2015;8(1):31. https://doi.org/10.1186/s40413-015-0079-7. 
7. Arasi S, Corsello G, Villani A, Pajno GB. The future outlook on allergen immunotherapy in children: 2018 and beyond. Ital J Pediatr. 2018;44(1):80. https://doi.org/10.1186/s13052-018-0519-4

8. Halken S, Larenas-Linnemann D, Roberts G, Calderon MA, Angier E, Pfaar O, et al. EAACl guidelines on allergen immunotherapy: prevention of allergy. Pediatr Allergy Immunol. 2017;28(8):728-45. https://doi.org/10.1111/pai.12807.

9. Rodriguez SO. Sublingual immunotherapy in allergic rhinitis and asthma in 2-5 year-old children sensitized to mites. Rev Alerg Mex. 2008;55:71-5.

10. Rice JL, Diette GB, Suarez-Cuervo C, Brigham EP, Lin SY, Ramanathan MJ, et al. Allergen-specific immunotherapy in the treatment of pediatric asthma: a systematic review. Pediatrics. 2018;141(5):e20173833. https://doi.org/10.1 542/peds.2017-3833.

11. Epstein TG, Liss GM, Murphy-Berendts K, Bernstein DI. AAAAl and ACAAI surveillance study of subcutaneous immunotherapy, Year 3: what practices modify the risk of systemic reactions? Ann Allergy Asthma Immunol. 2013; 110:274-8 278.e1.

12. Rodriguez PN, Ambriz MMJ. Safety of immunotherapy and skin tests with allergens in children younger than five years. Rev Alerg Mex. 2006;53:47-51.

13. Wang J, Wu Y, Li J, Huang X, Zhu R. Eight aeroallergen skin extracts may be the optimal panel for allergic rhinitis patients in Central China. Int Arch Allergy Immunol. 2017;173(4):193-8. https://doi.org/10.1159/000479429.

14. Liu JL, Ning WX, Li SX, Xu YC, Wu L, Wang YS, et al. The safety profile of subcutaneous allergen immunotherapy in children with asthma in Hangzhou, East China. Allergol Immunopathol (Madr). 2017;45(6):541-8. https://doi.org/10.1016/j.aller.2017.04.002.

15. Li J, Wu Y, Yang Y, Huang N, Li W, Zhang S, et al. The efficacy and safety of two commercial house dust mite extracts for allergic rhinitis: a head-tohead study. Int Forum Allergy Rhinol. 2019;9(8):876-82. https://doi.org/10.1 002/alr.22343

16. Kopp MV, König IR, Friedrichs F, Umpfenbach HU, Niggemann B, MillnerUhlemann M. Comparison of six different allergen extracts for subcutaneous specific immunotherapy in children: an open-Labelled, prospective, controlled observational trial. Int Arch Allergy Immunol. 2019;180(4):284-90. https://doi.org/10.1159/000503104.

17. Bousquet J, Schunemann HJ, Samolinski B, Demoly P, Baena-Cagnani CE, Bachert $C$, et al. Allergic rhinitis and its impact on asthma (ARIA): achievements in 10 years and future needs. J Allergy Clin Immunol. 2012; 130(5):1049-62. https://doi.org/10.1016/j.jaci.2012.07.053.

18. Pfaar O, Demoly P, Gerth WWR, Bonini S, Bousquet J, Canonica GW, et al. Recommendations for the standardization of clinical outcomes used in allergen immunotherapy trials for allergic rhinoconjunctivitis: an EAACl position paper. Allergy. 2014;69(7):854-67. https://doi.org/10.1111/all.12383.

19. Tankersley MS. How should allergists deal with local reactions to allergen immunotherapy? Curr Allergy Asthma Rep. 2011;11(2):115-21. https://doi. org/10.1007/s11882-010-0172-5.

20. Lieberman P, Tankersley M. Significance of large local reactions that occur during allergen immunotherapy. J Allergy Clin Immunol Pract. 2015;3(2): 310-1. https://doi.org/10.1016/j.jaip.2014.03.011.

21. Cox L, Larenas-Linnemann D, Lockey RF, Passalacqua G. Speaking the same language: The World Allergy Organization Subcutaneous Immunotherapy Systemic Reaction Grading System. J Allergy Clin Immunol. 2010;125:569-74 574.e1-574.e7.

22. Cox LS, Sanchez-Borges M, Lockey RF. World Allergy Organization Systemic Allergic Reaction Grading System: Is a Modification Needed? J Allergy Clin Immunol Pract. 2017;5:58-62 e5.

23. Fiocchi A, Pajno G, La Grutta S, Pezzuto F, Incorvaia C, Sensi L, et al. Safety of sublingual-swallow immunotherapy in children aged 3 to 7 years. Ann Allergy Asthma Immunol. 2005;95(3):254-8. https://doi.org/10.1016/S1081-12 06(10)61222-7

24. Agostinis F, Tellarini L, Canonica GW, Falagiani P, Passalacqua G. Safety of sublingual immunotherapy with a monomeric allergoid in very young children. Allergy. 2005;60(1):133. https://doi.org/10.1111/j.1398-9995.2004.00616.x.

25. Coop CA, Tankersley MS. Patient perceptions regarding local reactions from allergen immunotherapy injections. Ann Allergy Asthma Immunol. 2008; 101(1):96-100. https://doi.org/10.1016/S1081-1206(10)60841-1.

26. Nelson BL, Dupont LA, Reid MJ. Prospective survey of local and systemic reactions to immunotherapy with pollen extracts. Ann Allergy. 1986;56(4):331-4.

27. Kartal O, Gulec M, Caliskaner Z, Musabak U, Sener O. Safety of subcutaneous immunotherapy with inhalant allergen extracts: a single-center 30-year experience from Turkey. Immunopharmacol Immunotoxicol. 2015;37(3):280 6. https://doi.org/10.3109/08923973.2015.1027918.
28. Webber CM, Calabria CW. Assessing the safety of subcutaneous immunotherapy dose adjustments. Ann Allergy Asthma Immunol. 2010; 105(5):369-75. https://doi.org/10.1016/j.anai.2010.09.003.

29. DaVeiga SP, Liu X, Caruso K, Golubski S, Xu M, Lang DM. Systemic reactions associated with subcutaneous allergen immunotherapy: timing and risk assessment. Ann Allergy Asthma Immunol. 2011;106:533-7 e2.

30. Chen J, Li B, Zhao Y, Zhang Q, Wan L, Liu J, et al. A prospective multicenter study of systemic reactions in standardized specific immunotherapy for allergic rhinitis in China. Am J Rhinol Allergy. 2014;28(1):e40-4. https://doi. org/10.2500/ajra.2014.28.4005.

31. Tophof MA, Hermanns A, Adelt T, Eberle P, Gronke C, Friedrichs F, et al. Side effects during subcutaneous immunotherapy in children with allergic diseases. Pediatr Allergy Immunol. 2018;29(3):267-74. https://doi.org/1 $0.1111 /$ pai.12847.

32. Epstein TG, Liss GM, Murphy-Berendts K, Bernstein DI. Immediate and delayed-onset systemic reactions after subcutaneous immunotherapy injections: ACAAI/AAAAI surveillance study of subcutaneous immunotherapy: year 2. Ann Allergy Asthma Immunol. 2011;107:426-31 e1.

33. Yu CL, Huang WT, Wang CM. Treatment of allergic rhinitis reduces acute asthma exacerbation risk among asthmatic children aged 2-18 years. J Microbiol Immunol Infect. 2019;52(6):991-9. https://doi.org/10.1016/j.jmii.201 8.10.003.

34. Cox L, Nelson H, Lockey R, Calabria C, Chacko T, Finegold I, et al. Allergen immunotherapy: a practice parameter third update. J Allergy Clin Immunol. 2011;127(1):S1-55. https://doi.org/10.1016/j.jaci.2010.09.034.

35. Pfaar O, Lou H, Zhang Y, Klimek L, Zhang L. Recent developments and highlights in allergen immunotherapy. Allergy. 2018;73(12):2274-89. https:// doi.org/10.1111/all.13652.

36. Roberts G, Pfaar O, Akdis CA, Ansotegui IJ, Durham SR, Gerth WWR, et al. EAACI guidelines on allergen immunotherapy: allergic rhinoconjunctivitis. Allergy. 2018;73(4):765-98. https://doi.org/10.1111/all.13317.

\section{Publisher's Note}

Springer Nature remains neutral with regard to jurisdictional claims in published maps and institutional affiliations.

Ready to submit your research? Choose BMC and benefit from:

- fast, convenient online submission

- thorough peer review by experienced researchers in your field

- rapid publication on acceptance

- support for research data, including large and complex data types

- gold Open Access which fosters wider collaboration and increased citations

- maximum visibility for your research: over $100 \mathrm{M}$ website views per year

At BMC, research is always in progress.

Learn more biomedcentral.com/submissions 